\title{
Sonoelastography and Dynamic Magnetic Resonance Mammogram in the Evaluation of BIRADS III and above Breast Lesions Categories- A Prospective Cohort Study
}

\section{ABSTRACT}

Introduction: Breast cancer has become a major health hazard in society. Early diagnosis of breast cancers plays a vital role in its management and control. Sonoelastography and Magnetic Resonance (MR) mammography are non invasive imaging methods in the diagnosis of breast lesions.

Aim: To determine the accuracy of sonoelastography and dynamic MR mammogram in the evaluation of breast masses of Breast Imaging Reporting and Database System score (BIRADS)-III and above (BIRADS-IV, V and VI ) lesion categories.

Materials and Methods: The present prospective cohort study conducted in the Department of Radiodiagnosis at Bowring and Lady Curzon Medical College and Research Institute and Prestige Medical Health Sciences, Bangalore, India from June 2019 to March 2020. A total of 60 female cases clinically and histopathologically diagnosed with breast cancers above 28 years of age were recruited. All the subjects underwent conventional B mode ultrasonogram. Cases with BIRADS-III and above lesion category were assessed through sonoelastography and dynamic contrast enhances MR mammogram. MR mammogram was performed by using 1.5 tesla GE Magnetic Resonance Imaging (MRI). The sequences like axial and sagittal Time (T)1 Weighted (W)1 and T2 WI, Diffusion Weighted Imaging (DWI), axial Short Inversion Time Inversion Recovery (STIR) were performed. The Chi-square test was used to compare the difference between study variables.

Results: A total of 60 female cases, clinically and histopathologically diagnosed with breast cancers above 28 years of age were included in the study with maximum in age range of 41-50 years. The dynamic MRI curve category sensitivity, specificity, positive predictive value (PPV), negative predictive value (NPV) and diagnostic accuracy as $91.8 \%, 95.3 \%, 96.3 \%, 92 \%$ and $94.8 \%$, respectively. The study showed sonoelastography sensitivity, specificity, positive predictive value, negative predictive value and diagnostic accuracy as $79.8 \%, 93 \%, 88.6 \%, 82.2 \%$ and $84 \%$, respectively.

Conclusion: The MR mammogram and sonoelastography are effective methods in the diagnosis of breast lesions; however, MR mammography has higher sensitivity, specificity and diagnostic accuracy.

Keywords: Accuracy, Breast cancer, Breast imaging reporting and data system, Predictive validity

\section{INTRODUCTION}

Breast cancer is a leading cancer type, representing $27.7 \%$ of all cancer types and accounts $11.1 \%$ of cancer deaths in India [1]. Even though, in every four minutes one woman in India diagnosed with breast cancer and in every 13 minutes one woman dies with breast cancer [2]. Breast cancer is the first or second leading cancer type among women with an estimated 2.3 million new cases and accounting $6.9 \%$ of total cancer deaths in females (1.8 million deaths) worldwide [3].

Different diagnostic modalities are available for the early diagnosis of breast cancer. Among them, few methods were used for screening the conditions, few used for diagnosis of disease severity and few used as adjunctive for evaluation. Adjunctive diagnostic methods provide additional confirmatory information to clinicians in the disease diagnosis [4]. Various methods like breast ultrasound, Computed Tomography (CT), Magnetic Resonance Imaging (MRI), mammography, thermography, optical imaging, and Positron Emission Tomography (PET) are widely used in the screening and diagnosis of breast cancers [5].

The MR mammography is non invasive breast imaging technique that depicts high quality images and has better sensitivity (over 90\%) and moderate specificity (72\%) for differentiating malignant and benign breast lesions [6-10]. The contrast-enhanced MRI determines tumour extent more accurately than mammography and ultrasound [11]. Ultrasonography has better sensitivity but has poor specificity. To overcome the downsides, above mention modalities Ultrasound (US) elastrography was introduced. US elastography is a non invasive widely accepted as a standard imaging diagnostic procedure for breast lesions and assesses tissue deformity by providing information on the elasticity [12]. The sonoelastography and B mode Ultrasonography (USG) together can effectively enhance the size while lesion demonstration and increase the specificity and positive predictive value in distinguishing the breast lesions.

However, US elastrography is operator dependent and there may be interobserver variability in the data interpretation [13]. BIRADS is a classification system proposed by American college of Radiology. It is implemented to standardise risk assessment and quality control for mammography and provide uniformity in the reports. BIRADS score includes $0-6$ categorisation, BIRADS 0 refers incomplete evaluation, BIRADS 1 refers negative examination, BIRADS 2 is consistent with benign findings, BIRADS 3 refers probably benign, BIRADS 4 refers chance of benign malignant, BIRADS 5 is highly suggestive of malignancy $>95 \%$ and BIRADS 6 refers malignancy [14]

With above literature support, the present study was designed to evaluate efficacy of sonoelastography and dynamic MR 
mammogram in the evaluation of breast masses of BIRADS-III and above lesion categories.

\section{MATERIALS AND METHODS}

The present prospective cohort study was conducted in the Department of Radiodiagnosis in association with Department of General Surgery at Bowring and Lady Curzon Medical College and Research Institute, Bangalore and Prestige Medical Health Sciences and Allied Health Sciences, Bangalore, India, from June 2019 to March 2020. A total of 60 female cases clinically and histopathologically diagnosed with breast cancers approached the department during study period were recruited. Cases above 28 years of age were considered because no reported cases found below that age group. After basic clinical examination and local palpation of the breast mass, Real-time conventional B-mode ultrasonography examination was performed to categorise BIRADS III and above lesions [13]. Informed consent was obtained from all the study participants and study protocol was approved by Institutional Ethics Committee (IEC/IRB NO: PMHS/ IEC/05/09).

Inclusion criteria: Cases with BIRADS III and above lesion categories, $>5 \mathrm{~mm}$ lesion in the mammary gland and cases willing to participate in the study were included.

Exclusion criteria: Cases with BIRADS I and II lesion categories, those with non solid breast lesions and the ones not willing to participate in the study were excluded from the study.

\section{Study Procedure}

All the subjects underwent sonoelastrogram and strain wave elastrogram with linear array transducer. MRI mammogram was performed by using 1.5 Tesla GE MRI. The sequences like axial and sagittal T1 Weighted Image (T1WI) and T2 Weighted Image (T2WI), Diffusion-Weighted Imaging (DWI) and axial Short Inversion Time Inversion Recovery (STIR) were performed. The elastography box was arranged to cover the whole lesion. The box was placed under the skin and subcutaneous tissue above, pectoralis major muscle below and $5 \mathrm{~mm}$ away on either sides of the lesion. Based on visual colour coding Tsukuba elasticity score 1-5 was implied to interpret the lesions [15]. MRI mammogram curves were reported as type 1, type 2 (Plateau pattern) and type 3 (Washout pattern) [16]. (Progressive Score 1 or 2 are considered as benign lesions, score 3 considered as probably benign and score 4 or 5 are considered as malignant lesions pattern). US elastrography and MRI mammogram images of study participants were reviewed by four radiologists (senior specialists in the departments) and they were unaware of Histopathological Examination (HPE) results and BIRADS category.

\section{STATISTICAL ANALYSIS}

The Statistical Package for Social Sciences (SPSS) version 23.0 software was used to carry out statistical analysis relevant to the study. Descriptive statistics were used to represent demographic and clinical characteristics in the form of frequency and percentages. Chi-square test was used to compare the difference between study variables. The predictive validity of MR mammography and US elastography against HPE expressed with 95\% confidence interval. The $p$-value of $<0.05$ was considered as statistically significant.

\section{RESULTS}

A total of 60 female cases clinically and histopathologically diagnosed with breast cancers above 28 years of age were recruited. Majority cases were in between 41-50 years [Table/Fig-1]. Bilateral lesions were more common (91\%).

BIRADS type III (45\%) and IV (35\%) lesions were more common than BIRADS type $\mathrm{V}(15 \%)$ and $\mathrm{VI}$ lesions (5\%) [Table/Fig-2]. HPE findings showed malignant lesion in 37\% cases and benign in $63 \%$. The comparison of HPE findings with sonoelastography

\section{Age wise distribution}

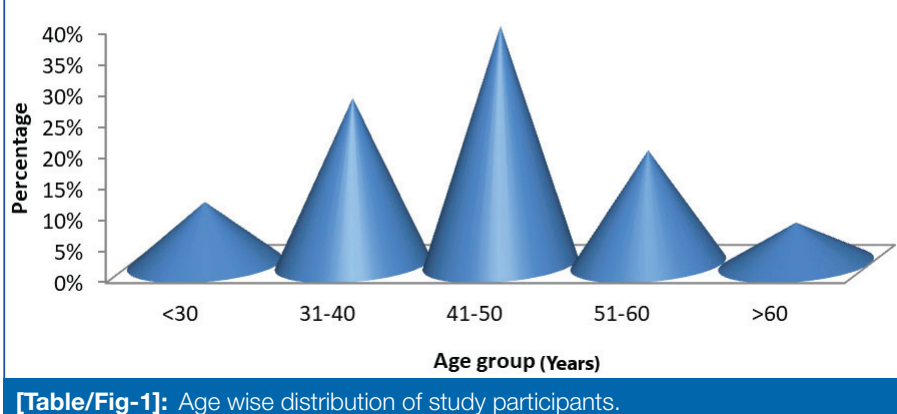

( $p$-value 0.00158) and MR curve category (p-value 0.0021) was statistically significant [Table/Fig-3].

\begin{tabular}{|l|c|c|}
\hline Findings & Frequency & Percentage \\
\hline Type of MRI curve & 28 & $46.7 \%$ \\
\hline Type 1 & 12 & $20 \%$ \\
\hline Type 2 & 20 & $33.3 \%$ \\
\hline Type 3 & 17 & $28.3 \%$ \\
\hline Score by sonoelastography & 21 & $35 \%$ \\
\hline Score 2 & 20 & $33.3 \%$ \\
\hline Score 3 & 02 & $3.33 \%$ \\
\hline Score 4 & 27 & $45 \%$ \\
\hline Score 5 & 21 & $35 \%$ \\
\hline BIRADS classification & 09 & $15 \%$ \\
\hline III & 03 & $5 \%$ \\
\hline IV & \multicolumn{2}{|c|}{} \\
\hline V & \multicolumn{2}{|c|}{} \\
\hline VI & \multicolumn{2}{|c|}{} \\
\hline [Table/Fig-2]: Radiological findings in cases with breast lesions. \\
MRI: Magnetic resonance imaging; BIRADS: Breast imaging reporting and data system
\end{tabular}

\begin{tabular}{l|l|c|c|c|}
\hline \multirow{2}{*}{ HPE findings } & \multicolumn{2}{|c|}{ MRI curve category } & \multicolumn{2}{c|}{ Sonoelastography grading } \\
\cline { 2 - 5 } & Malignant & Benign & Malignant & Benign \\
\hline Malignant & 19 & 03 & 16 & 03 \\
\hline Benign & 03 & 35 & 06 & 35 \\
\hline Chi-square value & \multicolumn{2}{|c|}{31.74} & \multicolumn{2}{|c|}{20.422} \\
\hline p-value & \multicolumn{2}{|c|}{$0.0021^{*}$} & \multicolumn{2}{c|}{$0.00158^{*}$} \\
\hline $\begin{array}{l}\text { [Table/Fig-3]: Comparison of HPE findings with sonoelastography and MR curve } \\
\text { category. } \\
\text { *Chi-square values of representing the comparison between variables. p-value < }<0.05 \text { is statistically } \\
\text { significant }\end{array}$
\end{tabular}

The predictive validity of MRI curve category showed sensitivity 91.8\%, specificity $95.3 \%$, positive predictive value (96.3\%), negative predictive value (92\%) and diagnostic accuracy (94.8\%). The sonoelastography findings had sensitivity $79.8 \%$, specificity $93 \%$, positive predictive value $88.6 \%$, negative predictive value $82.2 \%$ and diagnostic accuracy $84 \%$ [Table/Fig-4].

\begin{tabular}{|c|c|c|c|c|c|c|}
\hline \multirow{3}{*}{$\begin{array}{l}\text { Predictive } \\
\text { validity }\end{array}$} & \multicolumn{3}{|c|}{ MRI curve category } & \multicolumn{3}{|c|}{ Sonoelastography grading } \\
\hline & \multirow{2}{*}{$\begin{array}{l}\text { Outcome } \\
\text { value }\end{array}$} & \multicolumn{2}{|c|}{$95 \% \mathrm{Cl}$} & \multirow{2}{*}{$\begin{array}{l}\text { Outcome } \\
\text { value }\end{array}$} & \multicolumn{2}{|c|}{$95 \% \mathrm{Cl}$} \\
\hline & & Upper & Lower & & Upper & Lower \\
\hline Sensitivity & $91.8 \%$ & $100 \%$ & $77.22 \%$ & $79.8 \%$ & $91.22 \%$ & $55.8 \%$ \\
\hline Specificity & $95.3 \%$ & $99.9 \%$ & $80.45 \%$ & $93 \%$ & $99.9 \%$ & $84 \%$ \\
\hline PPV & $96.2 \%$ & $100 \%$ & $85.30 \%$ & $88.6 \%$ & $100 \%$ & $71.56 \%$ \\
\hline NPV & $92 \%$ & $100 \%$ & $84.68 \%$ & $82.2 \%$ & $95.6 \%$ & $68.17 \%$ \\
\hline Accuracy & $94.8 \%$ & $100 \%$ & $85.98 \%$ & $84 \%$ & $95.24 \%$ & $75.68 \%$ \\
\hline
\end{tabular}

[Table/Fig-4]: Comparison of predictive validity among sonoelastography and MRI curve category findings with HPE findings. HPE: Histopathological examination; MRI: Magnetic resonance imaging; PPV: Positive predictive value; NPV: Negative predictive value 

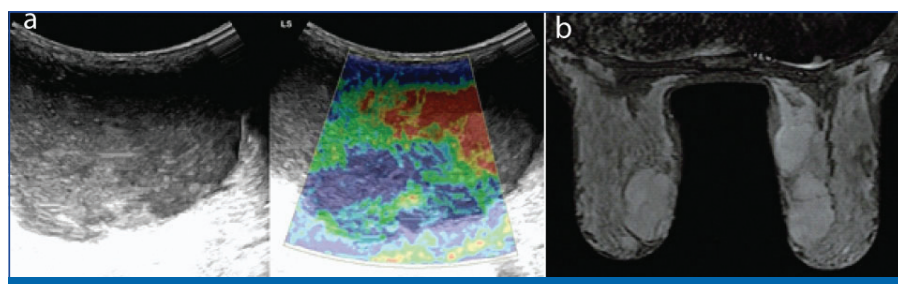

[Table/Fig-5]: A 29-year-old female case reported breast lesion on left side. a) USG image showing huge hypoechoic mass lesion and US elastrogram image representing lesion with elasticity score 3 (blue, green and red colour assorted amid); b) MR T2WI image representing bilateral hyper intense lesion with clear lesion limitations. concluded that MRI was the most sensitive imaging tool for the diagnosis of breast lesions with limited specificity due to overlap in features of benign and malignant lesions [18]. A study by Elmoneam GA et al., stated that dynamic MRI curve is more sensitive, specific and accurate than shear wave elastography [19]. A study by Shakweer MM et al., stated that sonoelastography and MR spectroscopy are effective non invasive diagnostic tools in the early diagnosis of breast malignancies [20]. The results of above studies were consistent with results of present study in which MR mammography has high predictive validity than US elastrography.

\begin{tabular}{|c|c|c|c|c|c|c|c|c|c|c|}
\hline \multirow[b]{2}{*}{$\begin{array}{l}\text { Predictive } \\
\text { validity }\end{array}$} & \multicolumn{5}{|c|}{ US elastrography } & \multicolumn{5}{|c|}{ MR mammogram } \\
\hline & $\begin{array}{l}\text { Present } \\
\text { study }\end{array}$ & $\begin{array}{c}\text { Parekh } \mathrm{H} \text { et al., } \\
{[17]}\end{array}$ & $\begin{array}{l}\text { Shakweer MM } \\
\text { et al., [20] }\end{array}$ & $\begin{array}{l}\text { EISaid } \\
\text { NA and } \\
\text { Mohamed } \\
\text { HGE [21] }\end{array}$ & $\begin{array}{l}\text { Ghazala S } \\
\text { et al., [18] }\end{array}$ & $\begin{array}{l}\text { Present } \\
\text { study }\end{array}$ & $\begin{array}{c}\text { Elmoneam GA } \\
\text { et al., [19] }\end{array}$ & $\begin{array}{l}\text { Ghazala S } \\
\text { et al., [18] }\end{array}$ & $\begin{array}{l}\text { Parekh H et } \\
\text { al., [17] }\end{array}$ & $\begin{array}{c}\text { EISaid NA and } \\
\text { Mohamed HGE } \\
\text { [21] }\end{array}$ \\
\hline Sensitivity & $79.8 \%$ & $87.5 \%$ & $90 \%$ & $83.3 \%$ & $86.7 \%$ & $91.8 \%$ & $100 \%$ & $66.7 \%$ & $95.6 \%$ & $84 \%$ \\
\hline Specificity & $93 \%$ & $84.4 \%$ & $85 \%$ & $86.7 \%$ & $87.8 \%$ & $95.3 \%$ & $92.3 \%$ & $91.5 \%$ & $91.3 \%$ & $84 \%$ \\
\hline PPV & $88.6 \%$ & - & $85.7 \%$ & - & $94.6 \%$ & $96.2 \%$ & - & $95.4 \%$ & - & - \\
\hline NPV & $82.2 \%$ & - & $89.4 \%$ & - & $66.8 \%$ & $92 \%$ & - & $53.3 \%$ & - & - \\
\hline Accuracy & $84 \%$ & - & $87.5 \%$ & - & $85.2 \%$ & $94.8 \%$ & $96.8 \%$ & $73.1 \%$ & - & - \\
\hline
\end{tabular}

[Table/Fig-6]: Comparison of predictive validity of present study with previous studies [17-21].

[Table/Fig-5] shows a young female case who reported breast lesion on left side. Ultrasonography image showed huge hypoechoic mass lesion and Ultrasound elastrogram showed lesion with elasticity score 3. The MR T2WI image of this patient represented bilateral hyper intense lesion with clear lesion limitations.

\section{DISCUSSION}

A total of 60 cases clinically and histopathologically diagnosed with breast cancers above 28 years of age were recruited. Majority cases were between $41-50$ years (38.30\%) followed by $31-40$ years (26.7\%), 51-60 years (18.3\%), 28-30 years $(10 \%)$ and above 60 years (6.67\%) [Table/Fig-1]. In this study, 91\% cases had breast lesions on bilateral side and $9 \%$ cases had unilateral breast lesions. A study by Parekh $\mathrm{H}$ et al., included 50 female cases between age group 20-60 years. Majority cases were in between 31-40 years (30\%), followed by 41-50 (28\%), 21$30(22 \%)$ and above 50 years (20\%) which is comparable with the present study [17].

Type 1 of MRI mammogram curve was seen in $46.7 \%$ cases, type 2 curve was seen in 20\% cases and type 3 curve was seen in $33.3 \%$ cases. The sonoelastography grading showed that $28.3 \%$ cases had grade 2 score, $35 \%$ had grade 3 score, $33.3 \%$ had grade 4 score and $33.3 \%$ had grade 5 score. In this study, BIRADS-III category lesions was seen in $45 \%$ cases, BIRADS-IV in $35 \%$, BIRADS-V in $15 \%$ and BIRADS-VI category in 5\% [Table/ Fig-2]. A study by Ghazala S et al., mammographic findings showed BIRADS-III category in 12 cases (probably benign-6, proved benign-5, malignant-1), BIRADS-IV category in 21 lesions (Malignant-19, benign-2) and BIRADS- $V$ category in 3 lesion which are malignant in nature [18].

In this study, histopathological findings showed malignant lesions in $37 \%$ cases and $63 \%$ cases had benign lesions. A study by Ghazala S et al., found $19.4 \%$ cases had benign lesions and $77.5 \%$ cases had malignant lesions by HPE [18]. The HPE findings showed that $41.3 \%$ had benign lesion and $58.7 \%$ cases had malignant lesions in a study by Elmoneam GA et al., [19]. The predictive validity of MRI curve category and sonoelastography values of present study was compared with the findings of previous studies mentioned in the [Table/Fig-6] [17-21].

A study by Parekh $\mathrm{H}$ et al., concluded that MRI evaluation of mammary lesion delivered higher sensitivity and specificity values than USG and mammography [17]. A study by Ghazala S et al.,

\section{Limitation(s)}

The present study was limited to BIRADS III and above lesion category with restricted number of participants for reliability and generalisability of the results.

\section{CONCLUSION(S)}

Sonoelastography and MR mammography are effective in differentiation of breast lesions, whereas Sonoelastography is a cost effective, specific and increase the diagnostic efficacy of breast lesion. The results of present study concluded that MR mammogram and sonoelastography are effective diagnostic tools in the diagnosis of breast lesions, whereas MR mammography has higher sensitivity, specificity and diagnostic accuracy. Further studies are required to evaluate the accuracy of MR mammography and US elastrography in breast lesion with larger sample size.

\section{REFERENCES}

[1] Malvia S, Bagadi SA, Dubey US, Saxena S. Epidemiology of breast cancer in Indian women. Asia Pac J Clin Oncol. 2017;13(4):289-95

[2] Bhattacharyya GS, Doval DC, Desai CJ, Chaturvedi H, Sharma S, Somashekhar SP. Overview of breast cancer and implications of overtreatment of early-stage breast cancer: An Indian perspective. CO Global Oncology. 2020;6:789-98. https://ascopubs.org/action/addCitationAlert?doi=10.1200/ GO.20.00033\&referrer=/.

[3] Sung H, Ferlay J, Siegel RL, Laversanne M, Soerjomataram I, Jemal A, et al. Global cancer statistics 2020: GLOBOCON estimates of incidence and mortality worldwide for 36 cancers in 185 countries.CA cancer. 2021;71(3):209-49.

[4] Santoro F, Podo F, Sardanelli F. MRI screening of women with hereditary predisposition to breast cancer: Diagnostic performance and survival analysis. Breast Cancer Res Treat. 2014;147(3):685-87.

[5] Sree SV, Ng EY, Acharya RU, Faust O. Breast imaging: A survey. World J Clin Oncol. 2011;2(4):171-78.

[6] Radhakrishna S, Agarwal S, Parikh PM, Kaur K, Panwar S, Sharma S, et al. Role of magnetic resonance imaging in breast cancer management. South Asian J Cancer. 2018;7(2):69-71.

[7] Kam JK, Naidu P, Rose AK, Mann GB. Five-year analysis of magnetic resonance imaging as a screening tool in women at hereditary risk of breast cancer. J Med Imaging Radiat Oncol. 2013;57(4):400-06.

[8] Screening for breast cancer: U.S. Preventive Services TaskForce recommendation statement. Ann Intern Med. 2009;151(10):716-26.

[9] Saslow D, Boetes C, Burke W, Harms S, Leach MO, Lehman CD, et al. American Cancer Society guidelines for breast screening with MRI as an adjunct to mammography. CA Cancer J Clin. 2007;57(2):75-89.

[10] Lehman CD, Smith RA. The role of MRI in breast cancer screening. J Natl Compr Canc Netw. 2009;7(10):1109-15.

[11] Peters NH, van Esser S, van den Bosch MA, Storm RK, Plaisier PW, van Dalen $\mathrm{T}$, et al. Preoperative MRI and surgical management in patients with nonpalpable breast cancer: The Monet-Randomised controlled trial. European Journal of Cancer. 2011;47(6):879-86

[12] Goddi A, Bonardi M, Alessi S. Breast elastography: A literature review. J Ultrasound 2012;15(3):192-98 
[13] Houelleu ML, Monghal C, Bertrand P, Vildé A, Brunereau L. An assessment of the performance of elastography for the investigationof BI RADS 4 and BI-RADS 5 breast lesions: Correlations with pathological anatomy findings. Diagn Interv Imag. 2012;93(10):757-66.

[14] Magny SJ, Shikhman R, Keppke AL. Breast Imaging Reporting and Data System. [Updated 2020 Sep 5]. In: StatPearls [Internet]. Treasure Island (FL): StatPearls Publishing; 2021 Jan.

[15] Itoh A, Ueno E, Tohno E, Kamma H, Takahashi H, Shiina T, et al. Breast disease: Clinical application of US elastography for diagnosis. Radiology, 2006;239(2):341-50.

[16] Moon M, Cornfeld D, Weinreb J. Dynamic contrast-enhanced breast MR imaging. Magn Reson Imaging Clin N Am. 2009;17(2):351-62.

[17] Parekh H, Kumari L, Vasavada D. Ultrasound, elastography and MR mammography correlation in breast pathologies (A study of 50 cases). EAS $J$ Radiol Imaging Technol. 2019;1(2):47-66.
[18] Ghazala S, Elgohary M, Zidan D, Yaftah M. Characterization of suspicious breast lesions with dynamic contrast enhanced MRI in comparison to conventiona mammography and ultrasonography. J Cancer Prev Curr Res. 2016;4(3):00121.

[19] Elmoneam GA, Almolla RM, Ahmed AF, Al Ekrashy MA. Supersonic shear waves quantitative elastography and kinetic magnetic resonance dynamic curve in discriminating BI-RADS 4 breast masses: A comparative study. The Egyptian Journal of Radiology and Nuclear Medicine. 2016;47(4):1773-82.

[20] Shakweer MM, AwadAllah AA, Sayed MM, Mostafa AM. Role of sonoelastography and MR spectroscopy in diagnosis of solid breast lesions with histopathological correlation. The Egyptian Journal of Radiology and Nuclear Medicine. 2015;46(4):1301-11.

[21] EISaid NA, Mohamed HGE. Sonoelastography versus dynamic magnetic resonance imaging in evaluating BI-RADS III and IV breast masses. The Egyptian Journal of Radiology and Nuclear Medicine. 2012;43:293-300. Doi: 10.1016/j. ejrnm.2012.03.001.

\section{PARTICULARS OF CONTRIBUTORS:}

1. Assistant Professor, Department of Radiology, Prestige Medical Health Sciences and Allied Health Sciences, Bengaluru, Karnataka, India

2. Senior Resident, Department of Radiology, Bowring and Lady Curzon Medical College and Research Institute, Bengaluru, Karnataka, India.

\section{NAME, ADDRESS, E-MAIL ID OF THE CORRESPONDING AUTHOR:}

\section{Shifa Farheen,}

Senior Resident, Department of Radiodiagnosis, Bowring and Lady Curzon Medical

College and Research Institute, Bangalore, Karnataka, India.

E-mail: shifz.sf@gmail.com
PLAGIARISM CHECKING METHODS: [Jain Het al.]

- Plagiarism X-checker: Apr 22, 2021

- Manual Googling: Oct 01, 2021

- iThenticate Software: Oct 09, $2021(14 \%)$
ETYMOLOGY: Author Origin

Date of Submission: Apr 21, 2021

Date of Peer Review: Jul 21, 2021

Date of Acceptance: Oct 01, 2021

Date of Publishing: Jan 01, 2022 